\title{
BLACK SWAN EVENT: AN EVIDENCE FROM CHINA'S ECONOMICS EFECTS
} Elena Stavrova ${ }^{1}$, Mariya Paskaleva ${ }^{2}$, Ani Stoykova ${ }^{3}$

\begin{abstract}
The prognosis of upcoming crises and the course of actually understanding them is increasingly becoming a major subject of discussions in pursuit of reliable indicators. The trade war between the United States and China, along with the COVID-19 pandemic are two events that took place in the Chinese economy with the aforementioned characteristics of the Black swan phenomenon, to which this latest professional analysis is devoted. The objective of this research is to examine the response of the Shanghai Stock Exchange Composite (SSEC) index, in addition to its relation with macroeconomic variables contributing towards a possible Black Swan Event. We employ an econometric methodology comprising of a unit root test, descriptive statistics, linear regression and correlation analysis for the period 2007-2019. Our results illustarte that the bubble from 2015, which is classified as a Black Swan event by many researchers, has a negative influence on the SSEC index. We can further deduce that there were some psychological effects on the Chinese stock market that lead to both, positive and negative trends of SSEC indices. The main findings confirmed that the Consumer Price Index, Exchange Rate, Interest Rate, Unemployment, GDP and Trade Balance were significantly elaborative macroeconomic variables, that had a substantial impact on the SSEC index.
\end{abstract}

JEL Classification Numbers: E44, G15, G17, H12, DOI: https://doi.org/10.12955/peb.v1.30

Keywords: Black Swan crisis and China's economy, macroeconomic indicators, stock market index, correlation.

\section{Introduction}

Over the past twenty years, China's economy experienced a complex transformation process, which, as stated by experts, has lead to an average $9.54 \%$ GDP growth. This has turned out to be a crucial prerequisite for the country's inclusion in global supply chains. The processes of transformation of China's national economy are both, external, for instance membership in the World Trade Organization, but also internal, like public sector reforms, accompanied by the advent of many new private companies, privatized state-owned enterprises, and investments in education. A demonstration of China's growing role in international financial markets was the integration of the Chinese national currency to the currency basket of SDR, the currency of the International Monetary Fund. China's position in the world's production of basic staple foods, essential for human consumption, must not be questioned, as this country contributes to $74 \%$ of pears, $54 \%$ of apples, $29 \%$ of rice, $23 \%$ of cotton $22 \%$ of corn production, to list a few; as recorded by the USDA.

Currently, China possesses a massive financial industry worth trillions of dollars. Its economy generated \$25.3 trillion in 2018, as per the International Monetary Fund, which makes China the world's largest economy. Still, the growth and development of its financial industry and that of FinTech innovations has given rise to numerous financial risks in China (Lerong, 2018). It is by virtue of these major variations in the international positioning of the Chinese economy, that experts emphasise on studying the effects of the crisis on its situation. According to Qichun Hey (2011), shocks related to financial conditions have played a major role again, since 2013. Specifically, financial tightening is evident mid2015 onwards. This was a period when China went through a steep decline in stock prices, exchange rate volatility and capital flight. Loan volumes dropped substantially during this period. Monetary relief helped to support the activity to some extent, but a revived financial tightening, towards the end of 2016, initiated a slowdown in production once again.

Several forseeable financial risks in China are outlined and determined as "Black Swans". In this article we acknowledge the description of Kishwar, Abbas and Ullah (2019) and that of Taleb (2007) and administer the same in the study. They elucidate it as a monthly return when the capital market index is higher than or equal to $( \pm)$ 5\% in absolute value, whereas Taleb (2007) defines it as an event with three attributes: i). It is an Outlier, ii). It has an intense effect on stock market returns, and iii). It has a predictable and plausible explanation as an aftermath. The Black Swan has three primary traits: rarity, strong impact and retrospective predictability. Therefore, Taleb (2007) alongside Kishwar, Abbas and Ullah (2019), concluded that high volatility of stock prices in the stock market is generally a result of the Black Swan. The principal objective this research is to review the reaction of the Shanghai Stock Exchange Composite (SSEC) index and the dynamic of the relation between the index and the eight

\footnotetext{
${ }^{1}$ South-West University “Neofit Rilski”-Blagoevgrad, Blagoevgrad, Bulgaria, helena_stavrova@abv.bg

${ }^{2}$ South-West University “Neofit Rilski”-Blagoevgrad, Blagoevgrad, Bulgaria, m.gergova@abv.bg

${ }^{3}$ South-West University “Neofit Rilski”-Blagoevgrad, Blagoevgrad, Bulgaria, ani_qankova_st@abv.bg
} 
macroeconomic indicators of China, before and after the Black Swan effect. We have incorporated the aforesaid variable because in the summer crash of the SSEC in 2015, Chinese investors lost about EUR 5 trillion, a sum greater than China's entire market capital in 2012. On 11 August 2015, the People's Bank of China (PBOC) announced its decision to liberalise the RMB reference rate, traditionally set by the central bank. This move set off a quick and significant depreciation of the Chinese currency. Furthermore, with the rapidly declining GDP and rising corporate debt, the values of the Chinese stock markets seemed to be "increasingly disconnected from reality" (Deng, 2015). All these macroeconomic factors appear to be connected to the unpredictable volatility of the SSEC.

Utilizing Statista, we implement an econometric methodology comprising of unit root tests, descriptive statistics, linear regression and correlation analysis based on monthly data for the period 2007-2019. China's stock market crash, on August 24, 2015, affected global stock markets, suggesting a possible Black Swan event. The explored time period is split into two sub-periods: January 2007-July 2015 and August 2015-December 2019, by dint of the Black Swan Event of August 2015 in China, when China's stock index lost $30 \%$ of its value in merely 3 weeks. Our findings exhibit that the Black Swan event of 2015 had a negative effect on the SSE Composite index. The key results validate that the relation between Consumer Price Index, Exchange Rate, Interest Rate, Unemployment, GDP and the SSEC index has notably transformed after the possible Black Swan event in China.

\section{Literature review}

Taleb (2007) takes the view that an event may be recognized as a Black Swan if it shows up unannounced or even if the event is expected, but it doesn't occur. In conformity to the theory of Taleb, there are three important criteria as concerns the qualifications of an event as a Black Swan: Unpredictability, which has a major impact; The outcome of the event, which may be either positive or negative and it may affect a larger group of people or an individual; Ex-post explanation, which explains the event after it has happened. Aven (2014) examines the way of addressing Black Swans in a risk context. He claims that various types of Black Swan events exist: unknown unknowns, unknown knowns (we do not have the knowledge, but others do), and events that are deemed to have a negligible probability of occurrence, and thus are not believed to occur. In his article, he reviews the present technique for tackling Black Swans, with the intention of gaining new insights by approaching the three types of Black Swans individually, motivated by the fact that they require different types of measures. He found that it is necessary to extend the current risk concepts and treatment frameworks with the purpose of involving the Black Swan risk. He develops a new generation of risk assessment and decision support methods that put greater emphasis on the Black Swan risk and offer a clearer picture of what the analysis captures and what lies within the management domain. Estrada (2009, pp. 1117) intends to quantify the impact of outliers on the long-term performance of the US stock market by the DJIA dynamics. He stresses on the following issues: "Do investors secure their long-term returns smoothly and steadily over time, or is their long-term performance largely determined by the return of just a few outliers?", and "Are investors likely to predict the best days to be in and out of the market successfully?" He further speculates that Black Swans do exist. Large daily swings that have a substantial impact on the long-term performance, unexpected ex-ante, although apparently predictable ex-post, take place much more frequently than they are usually believed to. As a matter of fact, investors come across them a lot more often than they expect, and the impact on their portfolios is far greater than they generally presume. Estrada (2009) finds proof of Black Swans having a massive impact on long-term performance in actuality. There are many authors that delineate the Black Swan effect as an event influenced by the macro and micro-environment of the country. Zhao et al. (2011) underline that the movements of stock markets are determined by colossal factors including overall economy, inflation, trading strategies, return on equity, market sentiment and the companies themselves. Also, it's intriguing that the Black Swan theory with its impact on the stock prices is mentioned as well. High volatility of stock prices in financial markets are usually a result of the Black Swans. It is on account of these events, which have a significant impact on future predictions, that there exists high volatility on stock market returns. These big shifts in volatility seem to correspond with important country-specific political, social and economic events (Aggarwal et al., 1999). Peša and Brajković (2016) examine the economic activity and stock exchange of Croatia as a new country of EU to investigate the 'Black Swan effect' from 2000 to 2013. The empirical findings obtained in the employment of the OLS method and the Chow Breakpoint Test provided evidence and revealed that the resignation of the Croatian Ex-Prime Minister lead the country successfully to the EU, but also was a 
'Black Swan event', having been unpredictable and resulting in a huge impact on the political and economic environment in Croatia as found through CROBEX, Croatian stock exchange indices. The authors conclude that the resignation was linked to one of the first instances of corruption in Croatia which entrained a negative impact on the economic development of the country in general, whilst parallely dealing with global recession. Christiano and Murhadi (2016) tested Black Swans anomalies in Indonesia. The goal of their research was to explore Black Swan anomalies that happened in BEI to stock indices LQ 45 using One Sample T-Test and Paired Sample T-Test. They came to the conclusion that Black Swan anomalies had two defining features, which are bleed and blowup. As and when Black Swan anomalies occur, they provoke overreaction in investors so that the price reversal and the winnerloser anomalies phenomenon ensues within the BEI. As per Lin and I-Chun (2019), China's stock market crash of August 24, 2015 affected global stock markets, suggesting a possible Black Swan event. They reassessed the trading days when sudden rises and drops occurred in the stock markets in 2015 for the purpose of inspecting the intraday fluctuation behaviors of stock prices to answer several questions like: (a) How did the market resume stability after volatility in stock prices occurred? (b) Did the corrections after days of sudden rises differ from those when sudden drops occurred? (c) Which of the investigated trading days could be classified as a consequence of Black Swan events? Five trading days with the highest and lowest daily returns in 2015, in the Shanghai and Shenzhen stock markets, were shortlisted as days of volatility. They applied the method of Unit Root Quantile Autoregression test. They aimed to verify whether stock price indices converged or dispersed on days of high volatility as time passed. The findings proved that a Black Swan event was recognized only for the sudden drop on May 28. On other trading days, China's stock markets showed prominent corrections of mean reversion, and the pace of market recovery increased, along with the extent of price volatility. According to Hiro Ito \& Ulrich Volz (2013), countries with persistent current account imbalances, such as China, are a sine qua non for a global rebalancing of the international economy. It is due to current account surpluses, in the wake of sectoral distortions, that Chinese households have paid a "financial repression tax". Restraint of disposable incomes has placed the country in a state of low quality social protection, and hence the threat posed by collapses in social systems such as health care and pension.

Hájek et al. (2019) evaluate the competitiveness through bankruptcy and creditworthiness models and compare it to financial conditions of the main competitors at that market. The authors juxtaposed data on selected poultry sector companies operating in Kazakhstan to study their competitiveness, while financial analysis metrics provided the financial performance data. They additionally compared the data with those of the Czech food industry. The results show that the Czech INFA metrics system can serve as a very useful indicator for competitiveness analysis of Kazakhstan companies. Hájek et al. (2019) affirm that there is a different perception of the risk associated with the indebtedness rate in the Czech Republic or Kazakhstan.

\section{Methodology}

Based on the research of Lin and I-Chun (2019) and the fact that they corroborate a Black Swan event during August 2015, we have segregated the explored time period using the following technique: January 2007-July 2015, as a pre-Black Swan event period, and August 2015-December 2019, as a postBlack Swan event period. We cover the structural break in August 2015, which marks China's stock market crash (August 24, 2015), that had a great impact on global stock markets as well. The day was coined after the Shanghai stocks plummeted $-8.5 \%$ with respect to the news of an economic slowdown in China's economy, but certain other factors contributed to the fall. Analogous to the American situation in 2008, Chinese companies were permitted to borrow cheaply from banks, which encouraged them to take undue risks in the stock market. As expected, the rate of borrowings soon exceeded the rate at which these invested companies could grow, triggering a major drawdown. Supplementarily, weak economic data worried the government to the point where it decided to weaken the Yuan's parity against the Dollar. China has traditionally been using the peg to manage its fiscal policy, since it's economy is heavily export-oriented. However, the plan backfired as China's stock index lost $30 \%$ of its value in 3 weeks, sparking a sell-off in other financial markets.

High volatility of stock prices is considered as a consequence of Black Swan events. According to a research by Marsh and Pfleiderer (2012), Black Swan events are evidenced to have strong influenes on future predictions and cause high volatility on the returns. Our dataset contains monthly observations at a country level over the years 2007-2019. The explored variables can be seen in Table 1, and the are: 


\begin{tabular}{|c|c|c|}
\hline Variable & Definition/Explanation & Source \\
\hline SSEC & The SSE Composite Index on a monthly basis & Yahoo Finance (2020) \\
\hline CPI & Consumer Price Index on a monthly basis & FRBSL (2020a). \\
\hline ER & $\begin{array}{l}\text { Exchange Rate expressed as the price of one unit of foreign } \\
\text { currency in units of domestic currency } \\
\text { (Chinese Yuan to One U.S. Dollar) on a monthly basis }\end{array}$ & FRBSL (2020b). \\
\hline IR & Interest Rate, Discount Rate for China on a monthly basis & IMF (2020). \\
\hline EPU & Economic Policy Uncertainty Index of China on a monthly basis & FRBSL (2020c). \\
\hline Unempl & $\begin{array}{l}\text { Unemployment expressed as a percentage of the total labor force } \\
\text { on a monthly basis }\end{array}$ & FRBSL (2020d). \\
\hline IPI & Industrial Production Index on a monthly basis & FRBSL (2020e). \\
\hline GDP & Gross Domestic Product on a monthly basis & FRBSL (2020f). \\
\hline Trbal & Trade Balance on a monthly basis & FRBSL (2020g). \\
\hline
\end{tabular}

Source: Authors

Note: More information about each of the variables can be obtained from the internet sources presented above.

Recent literature indicate that panel-based unit root tests have a higher power than unit roots tests based on individual time series. We define the Panel Unit Root Test by the following equation:

$$
y_{t}=p_{i} y_{i t-1}+x_{i t} \delta_{i}+\varepsilon_{i t}
$$

Where, $\mathrm{i}=1,2 \ldots \mathrm{N}$, are cross-section units, which are observed over time periods, $\mathrm{t}=1,2 \ldots T_{i} ; x_{i t^{-}}$ exogenous variables, including fixed effects or individual trends; $p_{i}$ - autoregressive coefficient; $\varepsilon_{i t}$ errors, assumed to be mututally independent idiosyncratic disturbances.

We may conclude that:

1. If $: p_{i}:<1, y_{i}$ is considered to trend consistently.

2. If $: p_{i}:=1$, then $y_{i}$ contains a unit root. The null hypothesis assumes a common unit root process.

Correlation refers to a broad class of statistical relationships involving interdependence, although in general use it often hints to the extent to which two variables have a linear relationship with each other.

The population correlation coefficient, $\hat{\rho}(X, Y)$, between two random variables $\mathrm{X}$ and $\mathrm{Y}$ is defined as:

$$
\hat{\rho}(X, Y)=\frac{\hat{\sigma}(X, Y)}{(\hat{\sigma}(X, X) \cdot \hat{\sigma}(Y, Y))^{1 / 2}}
$$

A correlation coefficient is a number that quantifies a type of correlation and dependence, which means statistical relationships between two or more values as per fundamental statistics.

To estimate the relation between the explored variables, we employ the correlation analysis. To exhibit the direct relationship between the SSE Composite (SSEC) index and macroeconomic indicators (MI) of China, we utilize linear regression in the form of the following equation:

$$
S S E C=\alpha M I+\beta
$$

Table 2 and Table 3 reveals that the mean is negative for all examined variables, except EPU and IPI, for both periods. The mean of the SSEC index before the Black Swan event is -0.004118511 , and this value varies between the minimum value of -1 and the maximum value of 0.206436115 . On the contrary, the mean of the SSEC index after the Black Swan event is -0.018319108 , and this value is between the minimum value of -1 and the maximum value of 0.137888238 . Examining these results, we can assume that the SSEC index decreases $77.5 \%$ after August 2015. This reduction in the value of the SSEC index occurs as a result of the Black Swan event in China, which has a great negative impact on the monthly returns of the SSEC index. Additionally, for both periods, the SSEC index is negatively skewed or lopsided, denoting a higher probability of a sharp decline in these series than rise. Moreover, in accordance to the higher value of the obliqueness for the second period, we can conclude that a Black Swan event is a negative event. Whenever a negative Black Swan event occurs, we should invest in a portfolio consisting of high beta stocks in order to benefit from the ascendance in the stock market, by 
virtue of mean reversion (Estrada and Vargas, 2010). The kurtosis values of stock prices before and after the standard adoption are greater than the values in the normal distribution (the kurtosis of which is 3 ), implying that big shocks are more likely to exist for these variables. On the other hand, big shocks are more likely to appear after the Black Swan event. We can prctically make the same assumptions because of the lower values of the means of the Consumer Price Index, Exchange Rate, Interest Rate, Economic Policy Uncertainty Index, Unemployment, GDP and Trade Balance after the Black Swan event as compared to these values before the Black Swan event. Accordingy, these macroeconomic indicators decrease after August 2015 and they are negatively influenced by the Black Swan event.

Table 2: Descriptive Statistics for the variables for the pre-Black Swan event period (January 2007July 2015)

\begin{tabular}{|c|c|c|c|c|c|c|c|c|c|}
\hline & dlog(SSEC) & dlog(CPI) & dlog(ER) & dlog(IR) & dlog(EPU) & dlog(Unemp) & dlog(IPI) & $\begin{array}{l}\operatorname{dlog} \text { (GDP) } \\
\text { (GDP }\end{array}$ & \begin{tabular}{|l|} 
dlog (Trade \\
Balance) \\
\end{tabular} \\
\hline Mean & \begin{tabular}{|l|}
-0.004118511 \\
\end{tabular} & -0.007310009 & -0.011738852 & -0.018844535 & 0.123059895 & -0.009916414 & 0.079462568 & -0.009804857 & \begin{tabular}{|l|}
-0.004884987 \\
\end{tabular} \\
\hline St.Err. & 0.013217972 & 0.009748626 & 0.009702182 & 0.014224052 & 0.065761806 & 0.009741373 & 0.090084059 & 0.009708892 & 0.013325086 \\
\hline Median & 0.007103111 & 0.001669406 & -0.001812989 & 0 & 0.018735354 & -0.000457451 & 0.013888889 & $1.88666 \mathrm{E}-05$ & 0.005086398 \\
\hline Mode & \#N/A & 0 & \#N/A & 0 & \#N/A & 0 & 0 & \#N/A & \#N/A \\
\hline St.Dev. & 0.134147762 & 0.098937751 & 0.098466395 & 0.14435836 & 0.667409438 & 0.098864136 & 0.914253347 & 0.098534488 & 0.135234856 \\
\hline Smpl.Var. & \begin{tabular}{|l|l}
0.017995622 \\
\end{tabular} & 0.009788678 & 0.009695631 & 0.020839336 & 0.445435357 & 0.009774117 & 0.835859182 & 0.009709045 & \begin{tabular}{|l|}
0.018288466 \\
\end{tabular} \\
\hline Kurtosis & 29.2073318 & 102.2894641 & 102.4176822 & 41.5104245 & 14.60930861 & 101.4995282 & 56.16121809 & 102.9521111 & \begin{tabular}{|l|}
29.08952994 \\
\end{tabular} \\
\hline Skewness & -4.0893120 & -10.09668 & -10.106109 & -6.2438028 & 2.962971072 & -10.037696 & 6.46029959 & -10.145391 & -3.9814502 \\
\hline Range & 1.2064361 & 1.026000 & 1.0209068 & 1.2432432 & 5.238624 & 1.05 & 9.809523 & 1.0027125 & 1.3486527 \\
\hline Min. & -1 & -1 & -1 & -1 & -1 & -1 & -1.809523 & -1 & -1 \\
\hline Max & 0.2064361 & 0.026000 & 0.0209068 & 0.2432432 & 4.238624 & 0.05 & 8 & 0.0027125 & 0.3486527 \\
\hline Sum & -0.4242066 & -0.75293 & -1.2091017 & -1.9409870 & 12.67516 & -1.0213905 & 8.184644 & -1.0099003 & -0.5031536 \\
\hline Count & 103 & 103 & 103 & 103 & 103 & 103 & 103 & 103 & 103 \\
\hline
\end{tabular}

Source: Authors

Notes: Summmary statistics of montly return series for Shanghai Stock Exchange Composite Index (SSEC), Consumer Price Index (CPI), Exchange Rate (ER), Interest Rate (IR), Economic Policy Uncertainty Index (EPU), Unemployment (Unempl), Industrial Production Index (IPI), Gross Domestic Product (GDP) and Trade Balance (Trbal) for China. Sample period is January 2007-July 2015. The return series are computed by taking the differences of variables first.

Table 3: Descriptive Statistics for the variables for the post-Black Swan event period (August 2015December 2019)

\begin{tabular}{|c|c|c|c|c|c|c|c|c|c|}
\hline & dlog(SSEC) & dlog(CPI) & $\operatorname{dlog}(E R)$ & dlog(IR) & $\operatorname{dlog}(\mathrm{EPU})$ & dlog(Unemp) & dlog(IPI) & dlog (GDP) & $\begin{array}{l}\text { dlog (Trade } \\
\text { Balance) }\end{array}$ \\
\hline Mean & -0.018319108 & -0.016926672 & $\begin{array}{l}-0.016889974 \\
\end{array}$ & \begin{tabular}{|l|}
-0.020899855 \\
\end{tabular} & 0.071844273 & -0.019332163 & 0.231079894 & -0.018867752 & \begin{tabular}{|l|}
-0.018029767 \\
\end{tabular} \\
\hline St.Err. & 0.020278359 & 0.018917148 & 0.018972983 & 0.01893813 & 0.046563973 & 0.018858997 & 0.22645881 & 0.01886795 & 0.022556521 \\
\hline Median & -0.003019385 & 0.000968992 & -0.000479122 & 0 & 0.027017881 & -0.000473255 & -0.071428571 & $8.65566 \mathrm{E}-06$ & -0.00686375 \\
\hline Mode & \#N/A & 0 & \#N/A & 0 & 0 & \#N/A & 0 & \#N/A & \#N/A \\
\hline St.Dev. & 0.147628685 & 0.137718913 & 0.138125398 & \begin{tabular}{|l|}
0.137871667 \\
\end{tabular} & 0.338990841 & 0.13729557 & 1.648645026 & 0.137360747 & 0.16421395 \\
\hline Smpl.Var. & 0.021794229 & 0.018966499 & 0.019078626 & \begin{tabular}{|l|}
0.019008597 \\
\end{tabular} & 0.114914791 & 0.018850073 & 2.718030421 & 0.018867975 & \begin{tabular}{|l|}
0.026966221 \\
\end{tabular} \\
\hline Kurtosis & 39.16897311 & 52.85904869 & 52.21167232 & \begin{tabular}{|l|}
51.71800502 \\
\end{tabular} & $\begin{array}{l}-0.181340928 \\
\end{array}$ & 52.99999993 & 36.34815931 & 52.99974075 & \begin{tabular}{|l|}
25.36516968 \\
\end{tabular} \\
\hline Skewness & -5.866798699 & -7.265834043 & $\begin{array}{l}-7.199901393 \\
\end{array}$ & \begin{tabular}{|l|}
-7.158890039 \\
\end{tabular} & 0.219775461 & -7.280109882 & 5.64989211 & -7.280083677 & \begin{tabular}{|l|}
-4.028127602 \\
\end{tabular} \\
\hline Range & 1.137888238 & 1.015825915 & 1.038870242 & 1 & 1.388460918 & 0.999532498 & 12.125 & 1.00036154 & 1.372065153 \\
\hline Min. & -1 & -1 & -1 & -1 & -0.572222 & -1 & -1.125 & -1 & -1 \\
\hline Max & 0.137888238 & 0.015825915 & 0.038870242 & 0 & 0.816238747 & -0.0004675 & 11 & 0.00036154 & 0.372065153 \\
\hline \multicolumn{10}{|l|}{ Sum } \\
\hline Count & -0.9709127 & -0.897113 & -0.8951686 & -1.1076923 & 3.807746447 & -1.0246046 & 12.24723436 & -0.999990 & -0.9555776 \\
\hline
\end{tabular}

Source: Authors

Notes: Summmary statistics of montly return series for Shanghai Stock Exchange Composite Index (SSEC), Consumer Price Index (CPI), Exchange Rate (ER), Interest Rate (IR), Economic Policy Uncertainty Index (EPU), Unemployment (Unempl), Industrial Production Index (IPI), Gross Domestic Product (GDP) and Trade Balance (Trbal) for China. Sample period is August 2015-December 2019. The return series are computed by taking the differences of variables first.

\section{Empirical analysis}

We apply the Panel Unit Root Test to calculate consistency (Levin et al., 2002) and further prove that all variables are stationary in the form $\operatorname{dlog}(\mathrm{x})$, i.e., variables were integrated of order 1 . In reference to the literature review, we also decided to incorporate these specific macroeconomic indicators in our models. The SSEC index is clearly correlated with most of the macroeconomic variables. It has a strong direct relationship with the Consumer Price Index (0.817278181), Exchange Rate (0.811758596), Unemployment (0.817185193) and GDP (0.819427421). Besides this, it also has a moderately positive relationship with the Interest Rate (0.579568063) and Trade Balance (0.607846433). 
Table 4: Correlation matrix of the examined variables for the whole examined period 2007-2019

\begin{tabular}{|c|c|c|c|c|c|c|c|c|c|}
\hline & \begin{tabular}{|l|l} 
dlog(SSEC) \\
\end{tabular} & dlog(CPI) & d dlog(ER) & dlog(IR) & 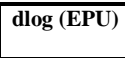 & $\begin{array}{l}\text { dlog } \\
\text { (Unempl) }\end{array}$ & dlog(IPI) & dlog(GDP) & $\begin{array}{l}\text { dlog(Trade } \\
\text { Balance) }\end{array}$ \\
\hline dlog(SSEC) & 1 & & & & & & & & \\
\hline $\operatorname{dlog}(\mathrm{CPI})$ & \begin{tabular}{|l|}
0.817278181 \\
\end{tabular} & 1 & & & & & & & \\
\hline $\operatorname{dlog}(E R)$ & \begin{tabular}{|l|}
0.811758596 \\
\end{tabular} & 0.995786808 & 1 & & & & & & \\
\hline dlog(IR) & \begin{tabular}{|l|}
0.579568063 \\
\end{tabular} & 0.790308822 & 0.78668778 & 1 & & & & & \\
\hline$d \log (E P U)$ & \begin{tabular}{|l|}
-0.005404202 \\
\end{tabular} & 0.119753613 & 0.12332383 & 0.15090975 & 1 & & & & \\
\hline dlog(Unempl) & \begin{tabular}{|l|}
0.817185193 \\
\end{tabular} & 0.997245294 & 0.99595128 & 0.78766595 & \begin{tabular}{|l|}
0.11961085 \\
\end{tabular} & 1 & & & \\
\hline dlog(IPI) & \begin{tabular}{|l|}
0.120183696 \\
\end{tabular} & 0.106006946 & 0.11438015 & 0.10823792 & \begin{tabular}{|l|}
-0.0148516 \\
\end{tabular} & 0.103774451 & 1 & & \\
\hline dlog(GDP) & \begin{tabular}{|l|}
0.819427421 \\
\end{tabular} & 0.998869103 & 0.99735002 & 0.79133649 & 0.12022404 & 0.998081508 & 0.106863515 & 1 & \\
\hline $\begin{array}{l}\text { dlog(Trade } \\
\text { Balance) }\end{array}$ & 0.607846433 & 0.787355456 & 0.77894113 & 0.58878941 & 0.16659331 & 0.782472562 & 0.073174503 & 0.778683517 & 1 \\
\hline
\end{tabular}

Source: Authors

Notes: Shanghai Stock Exchange Composite Index (SSEC); Consumer Price Index (CPI); Exchange Rate (ER); Interest Rate (IR); Economic Policy Uncertainty Index (EPU); Unemployment (Unempl); Industrial Production Index (IPI); Gross Domestic Product (GDP); Trade Balance (Trbal).

The results from the Linear Regression method display that the Consumer Price Index, Exchange Rate, Interest Rate, Unemployment, GDP and Trade Balance have a dynamic influence on the SSEC index owing to their significant p-values (lower than 0.01) before and after the Black Swan event. The impact of GDP on the SSEC index is positive for both periods. The coefficient value is significant at $1 \%$ level and is equal to 0.544799875 for the pre-Black Swan event period and 0.866250144 for the post-Black Swan event period. Taking into account the linear specification, this implies the following: if GDP increases by one standard deviation, the SSEC index also increases by $54.48 \%$ before august 2015 , and further increases by $86.62 \%$ after august 2015 . We can, thus surmise that the negative shocks and repurcussions of the Black Swan event lead to a stronger impact of GDP on the SSEC index. Furthermore, all the other statistically significant coefficients increase their values from the first to the second period and we observe a stronger impact of the Consumer Price Index, Exchange Rate, Interest Rate, Unemployment and Trade Balance on the SSEC index after the Black Swan event. Our findings verify the Exchange Rate as an important explanatory macroeconomic variable having a major influence on the SSEC index. The results also demonstrate that the Inflation Rate has a positive effect on the SSEC index in China for both periods, and the conclusions further reconfirm the Fisher hypothesis (1930) about a positive correlation between inflation and stock exchange volatility.

Table 5: Linear Regression analysis for China for the pre-Black Swan event period (January 2007July 2015) and for the post-Black Swan event period (August 2015-December 2019)

\begin{tabular}{|c|c|c|c|c|c|c|c|c|}
\hline \multicolumn{9}{|c|}{ Dependent variable: $\operatorname{dlog}($ SSEC $)$} \\
\hline \multicolumn{9}{|c|}{ Pre-Black Swan event period (January 2007-July 2015) } \\
\hline & $\begin{array}{l}\text { dlog } \\
\text { (CPI) }\end{array}$ & $\begin{array}{l}\text { dlog } \\
\text { (ER) }\end{array}$ & $\begin{array}{l}\text { dlog } \\
\text { (IR) }\end{array}$ & $\begin{array}{l}\text { dlog } \\
\text { (EPU) }\end{array}$ & $\begin{array}{l}\text { dlog } \\
\text { (Unempl) }\end{array}$ & $\begin{array}{l}\text { dlog } \\
\text { (IPI) }\end{array}$ & $\begin{array}{l}\text { dlog } \\
\text { (GDP) }\end{array}$ & $\begin{array}{l}\text { dlog } \\
\text { (Trade } \\
\text { Balance) } \\
\end{array}$ \\
\hline $\begin{array}{l}\text { Coefficient } \\
\text { (p-value) }\end{array}$ & $\begin{array}{l}0.545242581 \\
(4.8046 \mathrm{E})^{*}\end{array}$ & $\begin{array}{l}0.542608163 \\
\left(4.84473 E^{*}\right.\end{array}$ & $\begin{array}{l}0.428009889 \\
(3.17821 \mathrm{E})^{*}\end{array}$ & $\begin{array}{l}0.097155755 \\
(0.844775)\end{array}$ & $\begin{array}{l}0.543639167 \\
(6.28588 \mathrm{E})^{*}\end{array}$ & $\begin{array}{l}0.792898159 \\
(0.241878)\end{array}$ & $\begin{array}{l}0.544799875 \\
(3.2066 \mathrm{E})^{*}\end{array}$ & $\begin{array}{l}0.532744176 \\
(9.61326 \mathrm{E}- \\
09)^{*}\end{array}$ \\
\hline Multiple R & 0.739283759 & 0.73923363 & 0.39773636 & 0.019528083 & 0.737658573 & 0.116341399 & 0.741706638 & 0.528461679 \\
\hline R Square & 0.546540476 & 0.54646636 & 0.158194212 & 0.000381346 & 0.54414017 & 0.013535321 & 0.550128737 & 0.279271746 \\
\hline $\begin{array}{l}\text { Adjusted R } \\
\text { Square }\end{array}$ & 0.542050778 & 0.541975928 & 0.149859501 & -0.009515868 & 0.539626707 & 0.003768344 & 0.545674566 & 0.272135822 \\
\hline $\begin{array}{l}\text { Standard } \\
\text { Error }\end{array}$ & 0.066953101 & 0.066639571 & 0.133102831 & 0.670577409 & 0.067080121 & 0.91252911 & 0.066415859 & 0.115375558 \\
\hline Observations & 103 & 103 & 103 & 103 & 103 & 103 & 103 & 103 \\
\hline \multicolumn{9}{|c|}{ Post-Black Swan event period (August 2015-December 2019) } \\
\hline $\begin{array}{l}\text { Coefficient } \\
\text { (p-value) }\end{array}$ & $\begin{array}{l}0.866707082 \\
(1.11913 \mathrm{E}- \\
23)^{*}\end{array}$ & $\begin{array}{l}0.858468897 \\
(4.53883 \mathrm{E}- \\
22)^{*}\end{array}$ & $\begin{array}{l}0.862708313 \\
(6.61326 \mathrm{E}- \\
23)^{*}\end{array}$ & $\begin{array}{l}-0.238850481 \\
(0.458559926)\end{array}$ & $\begin{array}{l}0.865804548 \\
(5.74263 \mathrm{E}- \\
24)^{*}\end{array}$ & $\begin{array}{l}1.540967237 \\
(0.324463189)\end{array}$ & $\begin{array}{l}0.866250144 \\
(5.66688 \mathrm{E}- \\
24)^{*}\end{array}$ & $\begin{array}{l}0.805466901 \\
(8.913 \mathrm{E}-10)^{*}\end{array}$ \\
\hline Multiple R & 0.929072298 & 0.917533169 & 0.923761179 & 0.104018098 & 0.930966582 & 0.137986628 & 0.931003746 & 0.724116432 \\
\hline R Square & 0.863175335 & 0.841867115 & 0.853334716 & 0.010819765 & 0.866698777 & 0.019040309 & 0.866767976 & 0.524344608 \\
\hline $\begin{array}{l}\text { Adjusted R } \\
\text { Square }\end{array}$ & 0.860492498 & 0.838766471 & 0.850458927 & -0.008575926 & 0.864085027 & -0.000194194 & 0.864155583 & 0.515018031 \\
\hline $\begin{array}{l}\text { Standard } \\
\text { Error }\end{array}$ & 0.051438982 & 0.055462728 & 0.053315719 & 0.340441318 & 0.050616274 & 1.648805097 & 0.050627157 & 0.114359657 \\
\hline Observations & 53 & 53 & 53 & 53 & 53 & 53 & 53 & 53 \\
\hline \multicolumn{9}{|c|}{$\begin{array}{l}\text { Source: Authors } \\
\text { Notes: Significance levels are denoted as * significant at 1\%. Shanghai Stock Exchange Composite } \\
\text { Index (SSEC); Consumer Price Index (CPI); Exchange Rate (ER); Interest Rate (IR); Economic Policy } \\
\text { Uncertainty Index (EPU); Unemployment (Unempl); Industrial Production Index (IPI); Gross Domestic } \\
\text { Product (GDP); Trade Balance (Trbal). }\end{array}$} \\
\hline
\end{tabular}




\section{Conclusion}

Black Swan events can provoke catastrophic damage in an economy, and as they are virtually impossible to be predicted, only by building robust systems can they be prepared for. The results of this study reveal that a Black Swan event of 2015 had an adverse effect on the SSE Composite index and this unforeseen event affected the macroeconomic conditions in the economy of China. These findings can prove valuable for scientific researchers when the next "Black Swan event" happens. Authors reckon that there was some kind of psychological effects as well on the Chinese stock market that caused both, positive and negative trends in the SSEC indices. The results acknowledge that the Consumer Price Index, Exchange Rate, Interest Rate, Unemployment, GDP and Trade Balance are important explanatory macroeconomic variables that have a considerable impact on the SSEC index.

\section{References}

Aggarval, R. (1999) Volatility in Emerging Stock Market, Journal of Financial and Quantitative Analysis, 34(1), pp. 33-55.

Aven, T. (2014) Implications of black swans to the foundations and practice of risk assessment and management. Reliability Engineering \& System Safety. Volume 134. 2015. 83-91. ISSN 0951-8320.

Estrada, J. (2009) Black swans, market timing and the Dow: Applied Economics Letters. 16. 1117-1121.

Estrada, J. and Vargas, M. (2010) Black Swans, Beta, Risk, and Return. Working Paper. SSRN. Available at: http://papers.ssrn.com/sol3/papers.cfm?abstract_id=1692490

FRBSL (2020b). China / U.S. Foreign Exchange Rate [Data set]. Retrieved from: https://fred.stlouisfed.org/searchresults/?st=china, April 13, 2020.

FRBSL (2020c). Baker, Scott R., Bloom, Nick and Davis, Stephen J., Economic Policy Uncertainty Index for China [CHIEPUINDXM], retrieved from: FRED, Federal Reserve Bank of St. Louis; https://fred.stlouisfed.org/searchresults/?st=china, April 13, 2020.

FRBSL (2020d). Organization for Economic Co-operation and Development, Registered Unemployment Rate for China [LMUNRRTTCNQ156S]. Retrieved from: FRED, Federal Reserve Bank of St. Louis; https://fred.stlouisfed.org/searchresults/?st=china, April 13, 2020.

FRBSL (2020e). Organization for Economic Co-operation and Development, Industrial Production Index for China [PRINTO01CNQ663N], retrieved from: FRED, Federal Reserve Bank of St. Louis; https://fred.stlouisfed.org/searchresults/?st=china, April,13, 2020.

FRBSL (2020f). World Bank, Gross Domestic Product for China [MKTGDPCNA646NWDB], retrieved from: FRED, Federal Reserve Bank of St. Louis; https://fred.stlouisfed.org/searchresults/?st=china, April,13, 2020.

FRBSL (2020g). Trade Balance [Data set]. Retrieved from: https://fred.stlouisfed.org/searchresults/?st=china, April 13, 2020. Fisher, I. (1930) The Theory of Interest. New York. Macmillan. Retrieved from: http://files.libertyfund.org/files/1416/Fisher_0219.pdf

Hájek, P., Zhunissova, G., Oralbaeva, Z., Zhidebekkyzy, A., and Baidildina, A. (2019). Competitiveness and Economic Profit Analysis of Kazakhstan's Poultry Companies. Journal of International Studies, 12(2), 147-164. doi: 10.14254/20718330.2019/12-2/9.

Christianto, E. and Murhadi, W. R. (2016), Pengujian Black Swan Anomalies. Journal of Management and Business: 15 (1). IMF (2020). Interest Rates, Discount Rate for China [INTDSRCNM193N], Retrieved from: April 13, 2020, FRED, Federal Reserve Bank of St. Louis; https://fred.stlouisfed.org/series/INTDSRCNM193N

Ito, H.and Ulrich, V. (2013) China and Global Imbalances from a View of Sectorial Reforms”, Review of International Economics. 21(1), 57-71, DOI: 10.1111/roie.12020.

Kishwar, A., Abbas, S. and Ullah, S. (2019), The Impact of "Black Swan Events" on Beta and Returns: Evidence from Shanghai Composite Index and Pakistan Stock Exchange PSX (KSE-100). A Case Study of China and Pakistan. Available from:

https://www.researchgate.net/publication/333486905_The_Impact_of_Black_Swan_Events_on_Beta_and_Returns_Evidence _from_Shanghai_Composite_Index_and_Pakistan_Stock_Exchange_PSX_KSE-

100_A_Case_Study_of_China_and_Pakistan [accessed: Sep 29 2020].

Lerong, L. (2018) Black Swans and Grey Rhinos: Demystifying China's Financial Risks and the Financial Regulatory Reform. Butterworths Journal of International Banking and Financial Law. 594-597.

Levin, A., Chien-Fu, L. and Chia-Shang, J. Ch. (2002) Unit root tests in panel data: asymptotic and finite-sample properties. Journal of Econometrics. Elsevier. 108(1). 1-24.

Lin, Wen-Yuan and Tsai. I-Chun. (2019) Black swan events in China's stock markets: Intraday price behaviors on days of volatility. International Review of Economics \& Finance. Elsevier. 59(C). 395-411.

Marsh, T. and Pfleiderer, P. (2012) "Black Swans" and the Financial Crisis. Review of Pacific Basin Financial Markets and Policies. 15(02).

Peša, A. and Brajković, A. (2016) Testing the 'Black Swan Effect' on Croatian Stock Market Between 2000 and 2013. EMAJ: Emerging Markets Journal. 6.1.1-16.

Qichun H. (2011). Home-Bias Politics, Financial Deregulation and Economic Growth: A Causal Relationship. MPRA Paper. 
Statista (2020), Aviablable at www.statista.com[TT1]

Taleb, N. N. (2007) The Black Swan: Chapter 1: The Impact of the Highly Improbable. The New York Times. Retrieved: 20 January 2016.

Yahoo Finance (2020). SSE Composite Index, [Data set]. Retrieved from: https://finance.yahoo.com/quote/000001.SS/, April 13, 2020.Zhao, X., Yang, Juan, Zhao, L., Li, Q. (2011) The Impact of News on Stock Market: Quantifying the Content of Internet-based Financial News, The 11th International DSI and the 16th APDSI Joint Meeting, Taipei, Taiwan, July 12-16.

FRBSL (2020a). Consumer Price Index - Cross-country indices, [Data set]. Retrieved from:

https://fred.stlouisfed.org/tags/series?t=china\%3Bcpi, April 13, 2020. 